\title{
Histone H3 Acetyl Lys27
}

National Cancer Institute

\section{Source}

National Cancer Institute. Histone H3 Acetyl Lys27. NCI Thesaurus. Code C120023.

A post-translationally modified form of histone $\mathrm{H} 3$ where the lysine residue at position 27

is acetylated. This modification may be a marker for transcriptional enhancement. 